\title{
PALMEIRAS DO PARQUE NATURAL DO SERINGUEIRO, ACRE, BRASIL.
}

\section{Evandro FERREIRA ${ }^{1,2}$}

RESUMO - Dez gêneros e vinte e duas espécies de palmeiras foram encontradas no Parque Natural do Seringueiro, localizado no Municipio de Plácido de Castro (AC), sudoeste da Amazónia (10 20'S, 67 15'W). Embora contando com uma área de apenas 45 hectares a diversidade de gêneros e espécies é comparável à encontrada nos 10.000 hectares da Reserva Ducke, na Amazonia central. A alta diversidade verificada, combinada com a elevada taxa de destruição da cobertura vegetal na região de Plácido de Castro, demonstram a urgente necessidade de se estabelecer novas áreas de proteção para a flora local.

Palavras-chave: Arecaceae; Acre; Parque Natural.

Palms of Parque Natural do Seringueiro, Acre, Brazil.

ABSTRACT - Ten genera and 22 palm species were found in the Parque Natural do Seringueiro, municipality of Plácido de Castro, State of Acre, in the southwest Amazon. The park comprises only 45 hectares of area, however the generic and specific diversity found is comparable to that found in the 10,000 hectares Ducke Reserve in central Amazon. This high diversity and the intensive destruction of the forest in Plácido de Castro region demonstrates the urgent necessity for establishing more protected areas to preserve the local flora.

Key-words: Arecaceae; Acre; Native Park.

\section{INTRODUÇÃO}

\section{O Parque Natural do Seringueiro} possui uma área de 45 hectares e se encontra localizado a $3,5 \mathrm{~km}$ do centro da cidade de Plácido de Castro $\left(10^{\circ} 20^{\prime} \mathrm{S}, 67^{\circ}\right.$ $\left.15^{\prime} \mathrm{W}\right)$, capital do municipio homônimo (Fig. 1). Com uma extensão territorial de $2.972 \mathrm{~km}^{2}$, este municipio apresenta uma das maiores taxas de desmatamento do estado do Acre. De acordo com FUNTAC (1990), a média relativa de alteração da cobertura vegetal de todo o estado é de $4,15 \%$ mas em Plácido de Castro este indice sobe para $13,75 \%$. Este elevado percentual é resultado direto da intensa atividade agropecuária ali desenvolvida visto que o município possui $52,71 \%$ de seu território ocupado por projetos de colonização agrícola.

Criado em 1992, o Parque tem como objetivos básicos a preservação do ambiente natural típico da região e o desenvolvimento de atividades ecoturísticas e educacionais. Sua infraestrutura está constituida por diversas trilhas ecológicas e uma sede que procura representar, em pequena escala, a organização de um seringal, área extrativista tradicionalmente usada para a exploração de látex de seringueira (Hevea brasiliensis (Willd. ex Juss.) Muell. Arg.) e coleta de castanha do Brasil (Bertholletia excelsa H. B. K.), na Amazônia ocidental Brasileira.

As seguintes tipologias vegetais são encontradas na área do Parque:

1 Instituto Nacional de Pesquisas da Amazônia-INPA, Núcleo do Acre, Caixa Postal 73, Rio Branco-Acre, CEP 69.908-420.

2 Presente endereço para correspondência com o autor: Institute of Systematic Botany, The New York Botanical Garden, Bronx, NY 10458. 
mata primária inundável (várzea), mata primária de terra firme com sub-bosque antropizado, capoeiraalta e campo sujo (pastagem abandonada) (Fig. 1). Com exceção da mata primária encontrada em volta do perimetro da área situada entre os igarapés Alvoredo e Visionário, todas as demais áreas limitrofes do Parque são ocupados por pastagens cultivadas. A cada dois ou três anos os proprietários destas áreas promovem a sua queima com o objetivo de facilitar o processo de renovação destas. Em razão disso as áreas de mata primária de sub-bosque antropizado, capoeira alta e principalmente campo sujo são sujeitas a pequenos incêndios, que invariavelmente resultam em danos importantes à já reduzida superficie do Parque.

A hidrografia da área é fortemente influenciada pelo rio Abunã, localizado a cerca de $5 \mathrm{~km}$ ao sul do parque. A partir do mês de janeiro, com a elevação do nivel das águas deste rio, toda a extensão de mata primária contígua ao igarapé Visionário e parte da capoeira alta são inundadas, permanecendo nesta condição por um periodo de aproximadamente dois ou três meses, de acordo com a maior ou menor intensidade das chuvas.

Oliveira \& Alvarenga (1985) encontraram na região de Plácido de Castro solos predominantemente do tipo Podzolico Vermelho-Amarelo Distrófico, em sua maioria bem drenados. Dentro do Parque, entretanto, os solos são extremamente argilosos e pobremente drenados, ficando permanentemente encharcados durante todo o período das chuvas.

O clima na região é classificado como do tipo Ami, de acordo com o sistema de Köppen. A pluviosidade pode variar entre $1.750-2.250 \mathrm{~mm}$ por ano, A estação das chuvas começa em meados de outubro e termina na segunda quinzena de abril. Operiodo seco é mais severo entre julho e setembro. A temperatura média anual varia entre $22^{\circ} \mathrm{C}$ na estação seca e $26^{\circ} \mathrm{C}$ na estação chuvosa. A umidade do ar é elevada, acima de $80 \%$ a maior parte do ano (Brasil, 1976).

\section{MATERIAL E MÉTODOS}

Quatro excursões à área do Parque foram realizadas entre 1994 e 1995 , resultando na coleta de 42 amostras botânicas que se encontram depositadas no herbário da Universidade Federal do Acre (UFAC). Uma chave foi organizada com o objetivo de facilitar a identifícação a nível de campo de todas as espécies que crescem dentro da área do Parque. Para cada espécie é apresentada uma breve descrição de suas principais características baseadas nas coleções realizadas.

\section{RESULTADOS}

Dez gêneros e vinte e duas espécies de palmeiras foram identificadas (Tab. 1). Bactris é o gênero com maior número de espécies (7), uma das quais ainda não identificada a nivel específico por ter sido coletada apenas com frutos velhos.

Chelyocarpus chuco é a espécie mais frequente, podendo ser encontrada em todas a tipologias vegetais que compõem o Parque, enquanto que Bactris acanthocarpa, B. brongniartii, Bactris sp. e Oenocarpus minor apresentam distribuição mais restrita 


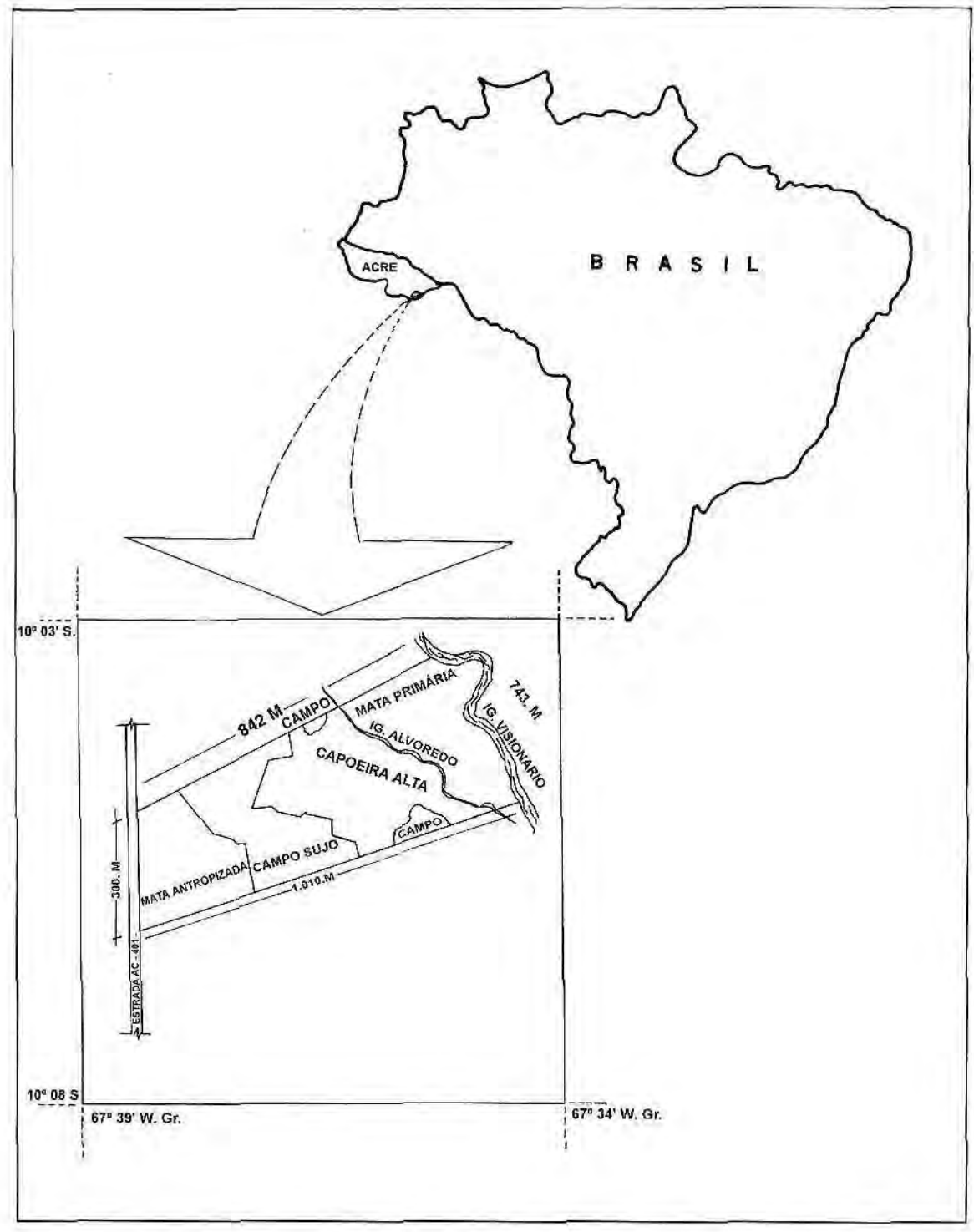

Figura 1. Localizaçào do Parque Natural Municipal do Seringueiiro. 
Tabela 1. Lista das espécies indentificadas

Astrocaryum aculeatum G. Meyer

Astrocaryum ulei Burret

Attalea butyracea (Mutis ex L. f.) Wess. Boer

Bactris acanthocarpa (Mart.) Henderson

Bactris brongniartii Mart.

Bactris concinna Mart.

Bactris concinna Mart.

Bactris major jacq.

Bactris maraja Mart.

Bactris simplicifrons Mart.

Bactris sp.

Chelycarpus chuco (Mart.) H. E. Moore
Desmoncus mitis Mart.

Eutterpe precatoria Mart.

Geonoma acaulis Martius

Geonoma deversa (Poit.) Kunth

Geonoma juruana Dammer

Geonoma maxima (Poit.) Kunth

Geonoma maxima (Poit.) Kunth

Maximiliana maripa (Aubl.) Drude

Oenocarpus bataua Mart.

Oenocarpus mapora H. Karsten

Oenocarpus minor Mart.

Socratea exorrhiza (Mart.) H. Wendi

Tabela 2. Tipologias vegetais e espécies associadas

\begin{tabular}{|c|c|c|c|c|}
\hline Espécies & Mata Inund. & Mata $\mathrm{TF}^{2}$ & Cap. Alta ${ }^{3}$ & Camp. Sujo ${ }^{4}$ \\
\hline Astrocaryum aculeatum & & $\mathrm{x}$ & $x$ & $x$ \\
\hline Astrocaryum ulei & & $x$ & $\mathrm{x}$ & $x$ \\
\hline Attalea butyracea & & $x$ & & $\mathrm{x}$ \\
\hline Bactris acanthocarpa & & $x$ & & \\
\hline Bactris brongniartii & $x$ & & & \\
\hline Bactris concinna & $x$ & $x$ & & \\
\hline Bactris major & & $x$ & & $x$ \\
\hline Bactris maraja & $\mathrm{x}$ & $x$ & & \\
\hline Bactris simplicifrons & $x$ & $x$ & & \\
\hline Bactris sp & $\mathrm{x}$ & & & \\
\hline Chelyocarpus chuco & $\mathrm{x}$ & $\mathrm{x}$ & $x$ & $x$ \\
\hline Desmoncus mitis & $\mathrm{x}$ & $x$ & & \\
\hline Euterpe precatoria & & $x$ & & $\mathrm{x}$ \\
\hline Geonoma acaulis & $x$ & $x$ & & \\
\hline Geonoma deversa & $x$ & $\mathrm{x}$ & & \\
\hline Geonoma juruana & $x$ & $x$ & & \\
\hline Geonoma maxima & $x$ & $x$ & & \\
\hline Maximiliana maripa & & $\mathrm{x}$ & & $x$ \\
\hline Oenocarpus bataua & $x$ & & $\mathrm{x}$ & \\
\hline Oenocarpus mapora & $x$ & $x$ & & \\
\hline Oenocarpus minor & & $x$ & & \\
\hline Socratea exorrhiza & $x$ & $x$ & & \\
\hline
\end{tabular}

1-Mata primária inundável; 2- Mata primária de terra-firme com sub-bosque antropizado;3-Capoeira alta; 4- Campo sujo. 
Chave de identificação das espécies

1. Folhas palmadas; flores hermafroditas...

1. Chelyocarpus chuco

1. Folhas pinadas ou quando inteiras com nervação pinada; flores unisexuais (2).

2. Palmeiras com espinhos (3).

3. Estipe escandente; pinas apicais modificadas em ganchos.

2. Desmoncus mitis

3. Estipe ereto ou inclinado; pinas apicais não modificadas (4).

4. Face abaxial das pinas cinza ou esbranquiçada (5).

5. Frutos globosos, epicarpo glabro; pinas irregularmente arranjadas em grupos e dispostas em vários planos........ 3. Astrocaryum aculeatum

5. Frutos turbinados ou oblongos, epicarpo setoso ou piloso; pinas regularmente arranjadas e dispostas em um mesmo plano........ 4. Astrocaryum ulei

4. Face abaxial dos folíolos verde ou marrom (6).

6. Frutos maduros de coloração vermelha ou laranja (7).

7. Frutos glabros; folhas inteiras, bifidas, raque medindo 4.5$8.5 \mathrm{~cm}$ de comprimento.

\section{Bactris simplicifions}

7. Frutos com espinulos negros no epicarpo; folhas pinadas, raque medindo 1.30-1.31 mde comprimento..

6. Bactris acanthocarpa

6. Frutos maduros de coloração negra ou violácea (8).

8. Espinhos achatados e amarelados; raque da inflorescência alongada (9)

9. Inflorescência com ate 10 raquilas; pinas sigmóideas.... 7. Bactris maraja 9. Inflorescência com 24-30 raquilas; pinas linear-lanceoladas 8. Bactris brongniartii

8. Espinhos não achatados, negros; raque da inflorescência ausente ou muito curta (10).

10. Inflorescência espigada; pinas regularmente arranjadas e dispostas em um plano

9. Bactris concinna

10. Inflorescência com três ou mais raquilas; pinas irregularmente arranjadas e dispostas em mais de um plano (11).

11. Inflorescência com 2-3 raquilas; frutos elipsoidais.

10. Bactris major

11. Inflorescência com

15-25 raquilas; frutos depressosglobosos. 11. Bactris sp.

2. Palmeiras sem espinhos (12).

12. Bainha foliar fechada formando um pseudo-caule (13).

13. Raizes adventicias de $2 \mathrm{~m}$ de altura; inflorescência com 6-11 raquilas..........12. Socratea exorrhiza

13. Raizes adventícias com até $40 \mathrm{~cm}$ de altura; inflorescência com 70-160 raquilas

13. Euterpe precatoria

12. Bainha foliar aberta não formando pseudo-caule (14).

14. Acaules ou caulescentes, com estipe de até $1.5 \mathrm{~cm}$ de diâmetro; folhas com até 14 pinas (15).

15. Acaules; inflorescência espigada............14. Geonoma acaulis

15. Caulescentes; inflorescência ramificada (16).

16. Alvéolos florais verticilados; follhas com as pinas falcadas. 
15. Geonoma deversa

16. Alvéolos florais espiralados; folhas com pinas levemente sigmóides (17).

17. Folhas com 2 pinas largas intercaladas por 1-2 pinas mais estreitas; frutos maduros verdeamarelados. 16. Geonoma juruana

17. Folhas com 24 pinas de largura similar; frutos maduros negropúrpura

17. Geonoma maxima

14. Estipe com mais de $9 \mathrm{~cm}$ diâmetro; folhas com mais de 47 pinas (18).

18. Inflorescência infrafoliar; frutos maduros de cor violácea (19)

19. Estipe solitário; flores estaminadas com 12-15 estames......

18. Oenocarpus bataua

19. Estipe cespitoso; flores estaminadas com 6 estames (20)

20. Pedúnculo da inflorêscencia com $5.4 \mathrm{~cm}$ de comprimento; até 54 raquilas na inflorescência...........

19. Oenocarpus minor

20. Pedúnculo da inflorescência com $6.5-10 \mathrm{~cm}$ de comprimento; $68-73$ raquilas na inflorescència.. ... 20. Oenocarpus mapora

18. Inflorescência intrafoliar; frutos maduros de cor marrom ou rosa (21)

21. Flores estaminadas com estames exertos; pinas irregularmente arranjadas em grupos e dispostas em mais de 1 plano

21. Maximiliana maripa

21. Flores estaminadas com estames não exertos; pinas regularmente arranjadas e dispostas em 1 plano 22. Attalea butyracea

\section{Chelyocarpus chuco (Martius) H. Moore, Principes 16: 73. 1972.}

"Caranai", "Carnaubinha", "Palha redonda" [Fig. 2c]

Estipe cespitoso (2), 7,77m de comprimento e $8,50 \mathrm{~cm}$ de diâmetro, liso, com cone de raizes na base alcançando $41 \mathrm{~cm}$ de altura. Folhas 10 , palmadas, com uma hástula muito curta dividindo a lâmina foliar em dois lados, cada um deles com 20-22 nervuras abaxialmente salientes subdividindo apicalmente cada lado em até 14 segmentos; bainha $25 \mathrm{~cm}$ de comprimento, aberta, muito fibrosa nas margens; peciolo $1.20 \mathrm{~m}$ decomprimento, transversalmente semi-ovalados. Inflorescência 4-5, intrafoliar na ântese, com até 4 ramificações secundárias; prófilo $24,5-30 \mathrm{~cm}$ de comprimento; bráctea peduncular 2 , $20-25 \mathrm{~cm}$ de comprimento, densamente coberta por pelos de cor dourada com aspecto de lã; pedúnculo $27-30 \mathrm{~cm}$ de comprimento; raquilas $31-38$ por ramificação secundária. Flores nascendo singularmente, hermafroditas, $4 \mathrm{~mm}$ de comprimento, com 3 sépalas e 3 pétalas, 6 estames e 3 carpelos livres. Frutos globosos, $1,4 \mathrm{~cm}$ de diâmetro, epicarpo liso, seco e quebradiço, esverdeado ou apenas levemente amarelados quando maduros.

$\mathrm{Na}$ área de mata antropizada podese observar que esta espécie é muito suscetivel aos fortes ventos que assolam a região em meados de outubro, no início da temporada de chuvas. É comum encontrar individuos com o estipe quebrado entre a sua base e a porção mediana, poucos deles conseguindo regenerar-se. $\mathrm{Na}$ área de 
campo sujo não foi observado tal fato, embora deva-se ressaltar que nestas condições $C$. chuco tende a desenvolver uma copa com folhas de menor porte, especialmente o peciolo muito curto, o que parece ser uma estratégia eficaz contra a ação dos ventos.

Exemplar representativo: E. Ferreira \& P. Silvio 289.

\section{Desmoncus mitis Martius, Hist. \\ Nat. Palm. 2: 90.1824.}

\section{"Jacitara"}

Estipe cespitoso (2-3), escandente, $2,15-4,20 \mathrm{~m}$ de comprimento e $0,4 \mathrm{~cm}$ de diâmetro, esverdeado, com espinhos recurvados ou menos frequentemente retos. Folhas 17-20, pinadas, 3-4 pinas lanceoladas por lado, regularmente arranjadas edispostas em um plano, pinas medianas $16-18,2 \mathrm{~cm}$ de comprimento e 4,5-5,6cm de largura; bainha fechada, verde, $16,5-19,2 \mathrm{~cm}$ de comprimento, ocrea pouco fibrosa, até $7 \mathrm{~cm}$ de domprimento; peciolo 2,5$6,5 \mathrm{~cm}$ de comprimento; raque 19,5 $27 \mathrm{~cm}$ de comprimento, com espinhos negros recurvados e base bulbosa verde. Inflorescência 1-3, intrafoliar; prófilo $18-24,5 \mathrm{~cm}$ de comprimento; bráctea peduncular $1,46,6 \mathrm{~cm}$ de comprimento, glabra ou raramente com espinhos retos, curtos e negros no ápice, verde-amareladas na ântese, tornando-se frágil, deiscente e escurecida na frutificação; pedúnculo $21,5-27,1 \mathrm{~cm}$ de comprimento; ráquis $2,17-7 \mathrm{~cm}$ de comprimento; raquilas 4 $7,3-7 \mathrm{~cm}$ de comprimento; ráquis e raquilas delgados, quase filiformes. Flores em tríades na base das raquilas, apicalmente somente estaminadas; flores estaminadas com 3 sépalas formando um tubo curto, 3 pétalas parcialmente unidas na base, livres e valvadas acima, 6 estames; flores pistiladas com 3 sépalas unidas, formando um tubo curto, 3 pétals unidas formando um tubo trilobado. Frutos elipsoidais, epicarpo liso, avermelhado ou laranjado quando maduro.

Espécie pouco frequente, sendo mais facilmente encontrada em locais bem iluminados, especialmente ao longo de trilhas e margens de vegetação próximas a áreas abertas.

Exemplares representativos: $\mathrm{E}$. Ferreira \& J. Bandeira 246, E. Ferreira \& P. Sílvio 297.

\section{Astrocaryum aculeatum G. Meyer, Prim. Fl. Essequib. 266. 1824.}

"Tucumã" [Fig. 2a]

Estipe solitário, $8 \mathrm{~m}$ de comprimento e $18 \mathrm{~cm}$ de diâmetro, $1 / 3$ apical do estipe com entre-nós densamente armados com espinhos negros e achatados. Folhas 7 , pinadas, 97-104 pinas lineares por lado, irregularmente arranjadas em grupos e dispostas em vários planos, pinas medianas $80,5 \mathrm{~cm}$ de comprimento e $3,7 \mathrm{~cm}$ de largura; bainha $47,5 \mathrm{~cm}$ de comprimento, fibras grosas em forma de pano nas margens; peciolo $75 \mathrm{~cm}$ de comprimento; raque $2,12 \mathrm{~m}$ de comprimento; bainha, pecíolo e raque armados com espinhos similares aos do estipe, $4,5-7,5 \mathrm{~cm}$ de comprimento. Inflorescência 1, intrafoliar, ereta na ântese; prófilo com ca. $70 \mathrm{~cm}$ de comprimento; bráctea peduncular 1 , com $1,24 \mathrm{~m}$ de comprimento, lenhosa, larga, externamente coberta por espinhos negros, finos, frouxamente 
arrranjados; pedúnculo $60 \mathrm{~cm}$ de comprimento; raque $1,21 \mathrm{~m}$ de comprimento; raquilas numerosas, dispostas em todos os lados da raque; raquilas basais $14,5 \mathrm{~cm}$ de comprimento, as apicais com $29,5 \mathrm{~cm}$ de comprimento. Flores 2-4 flores pistilada na base e numerosas flores estaminadas no ápice das raquilas; flores pistiladas com ca. de $6 \mathrm{~mm}$ de comprimento, 3 sépalas, 3 pétalas e 6 estames, densamente arranjadas na porçâo apical das raquilas; flores pistiladas com ca. $1,5 \mathrm{~cm}$ de comprimento, sépalas e pétalas cupulares. Frutos globosos, $3,4-4,0 \mathrm{~cm}$ de diầmetro, epicarpo liso, de cor amarelado quando maduro.

Encontrada em áreas alteradas e não sujeitas a inundações prolongadas. Ao longo das pastagens que margeiam a estrada que liga Plácido de Castro a Rio Branco, é, juntamente com A. butyracea e M. maripa, a espécie mais comum.

Exemplar representativo: E. Ferreira \& P. Silvio 286.

\section{Astrocaryum ulei Burret, Repert.} Spec. Nov, Regni Veg. 35:147. 1934.

\section{"Murumuru"}

Estipe solitário, $4 \mathrm{~m}$ de comprimento e $15,6 \mathrm{~cm}$ de diâmetro, $1 / 3$ final coberto por bainhas persistentes de folhas mortas. Folhas 7, pinadas, 100 pinas lineares por lado, regularmente arranjadas e dispostas em 1 plano, pinas medianas com $1,02 \mathrm{~m}$ de comprimento e $4,8 \mathrm{~cm}$ de largura; bainha com ca. de $80 \mathrm{~cm}$ de comprimento; pecíolo $1,10 \mathrm{~m}$ de comprimento; raque $4,26 \mathrm{~m}$ de comprimento; bainha, peciolo e raque armados com espinhos negros, achatados, medindo $3,5-12 \mathrm{~cm}$ de comprimento. Inflorescência 1, intrafoliar e ereta na ântese; prófilo com até $70 \mathrm{~cm}$ de comprimento; bráctea peduncular $1,1,20 \mathrm{~m}$ de comprimento,externamente densamente coberta por pelos finos e macios de coloração castanha ou negra; pedúnculo com ca. de $1 \mathrm{~m}$ de comprimento; raque $39-40 \mathrm{~cm}$ de comprimento; raquilas numerosas, dispostas em todos os lados da raque, até $14 \mathrm{~cm}$ de comprimento. Flores 1 flor pistilada na base e numerosas pequenas flores estaminadas no ápice das raquilas; flores estaminadas com ca. de $2-3 \mathrm{~mm}$ de comprimento, 3 sépalas, 3 pétalas e 6 estames; flores pistiladas com $1 \mathrm{~cm}$ de comprimento, cálice e corola cupulares, cálice muito curto, glabro. Frutos turbinados ou obovados-oblongos, $3 \mathrm{~cm}$ de comprimento e $2 \mathrm{~cm}$ de diâmetro, epicarpo densamente setoso ou com pelos de cor marrom.

O tipo de $A$, ulei, constituído de frutos e material vegetativo, foi coletado por E. Ule no início do século ao longo do rio Acre, nas proximidades da cidade de Brasiléia. $\mathrm{Na}$ falta de flores, Burret (1934) descreveu esta espécie baseando-se principalmente nos caracteres dos frutos. A falta de material adequado e a confusão que muitostaxonomistas fazem com relação à sua identidade e a de $A$. murumuru fez com que durante todos estes anos a mesma fosse quase sempre considerada uma sinonímia desta última. Embora com hábitos similares, duas características podem ser relacionadas como importantes na separação destas espécies: flores pistiladas com cálice 
muito curto (A. ulei) e frutos maduros muito maiores e mais carnosos, quase sempre oblongo-obovóides ( $A$. muruтuru).

Exemplar representativo: E. Ferreira \& P. Silvio 288.

\section{Bactris simplicifrons Martius,} Hist. Nat. Palm. 2:103. 1826.

Estipe cespitoso (11), 0,90-1,05m de comprimento e $0,25-0,50 \mathrm{~cm}$ de diâmetro, sem espinhos. Folhas 6-10, inteiras, lâmina foliar pilosa abaxialmente, espínulos nas margens, concentrados no ápice; bainha $8,6-12 \mathrm{~cm}$ de comprimento; pecíolo $8-11,5 \mathrm{~cm}$ de comprimento; raque $4,5-8,5 \mathrm{~cm}$ de comprimento; ápice da bainha, peciolo e raque com espinhos finos, negros ou de cor marrom clara com base e ápice enegrecidos, até $1,7 \mathrm{~cm}$ de comprimento. Inflorescência 3-4, infrafoliar, espigada, usualmente pêndula; prófilo $2,5-3,3 \mathrm{~cm}$ de comprimento; bráctea peduncular 1 , $8 \mathrm{~cm}$ de comprimento, ereta na ântese, glabra ou com escassos espinhos similares aos da bainha foliar; prófilo e bráctea peduncular frágeis, papiráceos; pedúnculo $4,2-5,5 \mathrm{~cm}$ de comprimento; raque $2,4-4,2 \mathrm{~cm}$ de comprimento. Flores arranjadas em triades ao longo da raque, de cor creme-amarelada na antese; flores estaminadas com 3 sépalas conectadas formando um cálice tri-lobado muito curto , 3 pétalas parcialmente conectadas, livres e valvadasacima, 6 estames; flores pistiladas com cálice e corola tubulares. Frutos globosos, $0,5 \mathrm{~cm}$ de diâmetro (maduros), até 16 frutos por cacho, epicarpo glabro, de cor avermelhada na madurez.
Espécie de pequeno porte, raramente ultrapassando $1 \mathrm{~m}$ de altura total, geralmente formando pequenas touceiras. Aparenta ser glabra, porém os espinhos podem ser encontrados nas margens do ápice da lâmina foliar.

Exemplares representativos: E. Ferreira 245, E. Ferreira \& J. Bandeira 248, E. Ferreira \& P. Silvio 299.

\section{Bactris acanthocarpa (Martius) Henderson. The palms of the Amazon, p. 171, 1995.}

Acaule, 2 plantas na touceira. Folhas 5-6, pinadas, 13-17 pinas linearlanceoladas por lado, irregularmente arranjadas em grupos de 2-3, dispostas em vários planos, pinas medianas com $54 \mathrm{~cm}$ de comprimento e $3,6 \mathrm{~cm}$ de largura; bainha com ca. de $5 \mathrm{~cm}$ de comprimento; pecíolo $1,18 \mathrm{~m}$ de comprimento; raque $1,3 \mathrm{~m}$ de comprimento; espinhos negros tubulares na bainha e $1 / 3$ inicial do pecíolo. Inflorescência 1, intrafoliar; profilo n.v.; bráctea peduncular densamente coberta por espinhos negros e finos; pedúnculo $21 \mathrm{~cm}$ de comprimento; ráquis $7 \mathrm{~cm}$ de comprimento; raquilas 23 , até $10 \mathrm{~cm}$ de comprimento. Flores n.v. Frutos depressos-globosos, 9-10 unidades por raquila, epicarpo setoso, avermelhado quando maduro.

Única espécie espinhosa e acaule encontrada no Parque. Presente apenas em mata com sub-bosque antropizado. Uma entre duas espécies (a outra é $A$. murumuru) a apresentar frutos com epicarpo setoso.

Henderson (1995) emendou a descrição de Martius da espécie B. acanthocarpa cujo tipo foi coletado na 


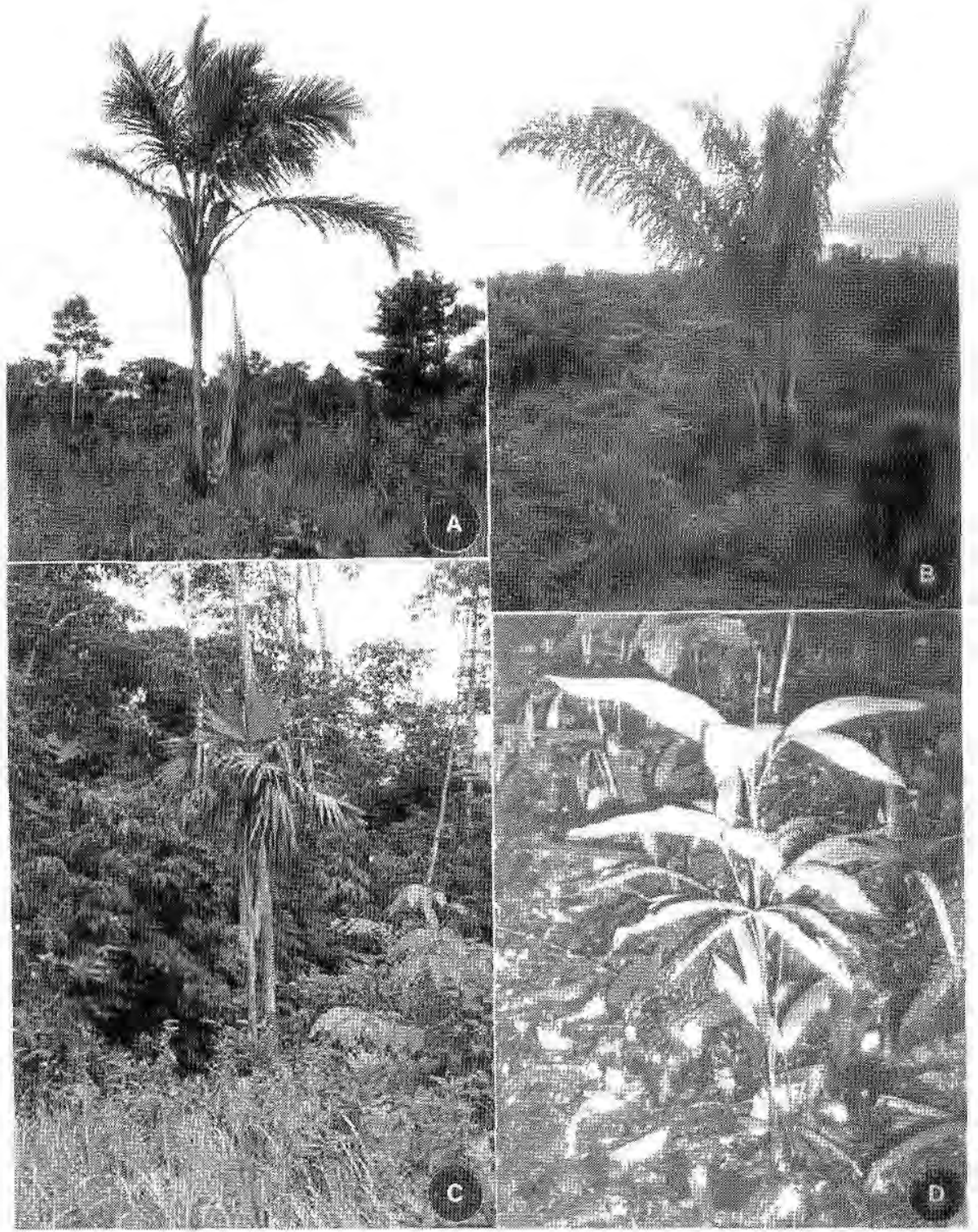

Figura 2. Palmeiras do Parque Natural do Seringueiro. A. Astrocaryum aculeatum; B. Maximiliana maripa; C. Chelycarpus chuco (observar as follhas com peciolo muito curto); D. Bactris simplicifrons. 
Bahia e considera $B$. humilis como sinonímia da mesma. Por muitos anos B. humilis foi usada para identificar as espécies amazônicas similares a $B$. acanthocarpa da costa Atlântica brasileira. B. humilis foi inicialmente descrita por Wallace (1853) como Astrocaryum humile sendo posteriormente transferida para Bactris por Burret (19331934), que se baseou apenas na ilustração contida na publicação de Wallace (não existe espécimen tipo em herbário).

Exemplar representativo: E. Ferreira \& J. Bandeira 249.

\section{Bactris maraja Martius, Hist.} Nat. Palm. 2:93. 1826.

\section{"Marajä"}

Estipe cespitoso (3), 2,26-2,32m de comprimento e $1,5-1,7 \mathrm{~cm}$ de diâmetro, espinhos achatados e amarelados com até $4,5 \mathrm{~cm}$ de comprimento próximos aos nós. Folhas 6-7, pinadas, $15-16$ pinas semisigmóideas por lado, irregularmente arranjadas em grupos e dispostas em vários planos; pinas medianas $26 \mathrm{~cm}$ de comprimento e $6,9 \mathrm{~cm}$ de largura; bainha $21 \mathrm{~cm}$ de comprimento, pouco fibrosas nas margens; pecíolo $34 \mathrm{~cm}$ de comprimento; ráquis $58 \mathrm{~cm}$ de comprimento; espinhos amarelados e achatados com até $4,8 \mathrm{~cm}$ de comprimento irregularmente distribuidos na bainha peciolo e raque. Inflorescência 1 , intrafoliar; prófilo $24,5 \mathrm{~cm}$ de comprimento; bráctea peduncular $1,33 \mathrm{~cm}$ de comprimento, escassamente coberta por espinhos achatados amarelados; pedúnculo $16 \mathrm{~cm}$ de comprimento; ráquis $2,5 \mathrm{~cm}$ de comprimento; raquilas 10 , com até $12,5 \mathrm{~cm}$ de comprimento. Flores n.v. Frutos depressos-globosos, epicarpo glabro, violáceo quando maduros, $1,3 \mathrm{~cm}$ de diâmetro e $1,6 \mathrm{~cm}$ de comprimento.

Embora pertencendo a um grupo de espécies extremamente complexo, no Parque esta espécie pode ser identificada sem maiores problemas pelas suas folhas com pinas sigmóideas, irregularmente arranjadas e dispostas em vários planos, espinhos achatados amarelados $\mathrm{e}$ brácteas pedunculares com escassos espinhos e sem tomentos marrons.

Exemplar representativo: E. Ferreira \& J. Bandeira 249.

\section{Bactris brongniartii Martius in A. D. Orb., Voy. Amérique Mér. 7(3). Palmiers 59. 1846.}

\section{"Marajá" [Fig. 3b]}

Estipe cespitoso (5), 2,25-4,46m de comprimento e $2-3,3 \mathrm{~cm}$ de diâmetro, entre-nós com 4,5-6cm de comprimento, com espinhos achatados e amarelados, até $7,7 \mathrm{~cm}$ de comprimento. Folhas 3-8, pinadas, 28-32 pinas linear-lanceoladas por lado, irregularmente arranjadas em grupos de 2-3, dispostas em vários planos, pinas medianas $56-74 \mathrm{~cm}$ de comprimento e $3,6-5,4 \mathrm{~cm}$ de largura, com ápice pêndulo; bainha $23-39 \mathrm{~cm}$ de comprimento; pecíolo $31-66 \mathrm{~cm}$ de comprimento; ráquis $0,97-1,77 \mathrm{~m}$ de comprimento; espinhos menores porém similares aos do estipe na bainha, peciolo e ráquis. Inflorescência 1 , intrafoliar; prófilo $18,5-23 \mathrm{~cm}$ de comprimento; bráctea peduncular 1,51$56 \mathrm{~cm}$ de comprimento, escassamente coberta por espinhosachatados amarelados; pedúnculo $29-37,5 \mathrm{~cm}$ de comprimento; ráquis $9,9-11,5 \mathrm{~cm}$ de comprimento; raquilas $24-30,10-20 \mathrm{~cm}$ de comprimento. Flores em triades, às 
vezes apenas flores estaminadas em pares ou solitárias; flores estaminadas com 3 sépalas formando um corola trilobada, 3 pétalas, 6 estames; flores pistiladas com cálice e corola tubulares, similares em comprimento, com visivel anel estaminoidal. Frutos depressosglobosos, 7 unidades por raquila, epicarpo glabro, púrpura quando maduros, $1,4 \mathrm{~cm}$ de diâmetro.

As folhas ascendentes com pinas linear-lanceoladas radiadas e dispostas em vários planos e a presença de espinhos amarelados e achatados, especialmente na bainha, peciolo e raque da folha são as principais características usadas na identificação preliminar desta espécie no campo. A outra espécie do Parque que apresenta espinhos achatados e amarelados, $B$. maraja, tem porte muito menor e folhas com pinas sigmóideas.

Exemplares representativos: E. Ferreira 485, E. Ferreira \& J. Bandeira $254,491$.

\section{Bactris concinna Martius, Hist. Nat. Palm. 2:99. 1826.}

\section{"Marajá" [Fig. 3a]}

Estipe cespitoso (19), 1,26-1,44m de comprimento e $1,-2,1 \mathrm{~cm}$ de diâmetro, espinhos negros de até $4 \mathrm{~cm}$ de comprimento nos entre-nós. Folhas 4-6, pinadas, 41-44 pinas linear-lanceoladas por lado, regularmente arranjadas e dispostas em um mesmo plano, pinas medianas $33,5 \mathrm{~cm}$ de comprimento e $2 \mathrm{~cm}$ de largura; bainha $27-29 \mathrm{~cm}$ de comprimento, parcialmente fechada, muito fibrosa nas margens; peciolo 49$58 \mathrm{~cm}$ decomprimento; ráquis 1,12 $1,21 \mathrm{~m}$ de comprimento; bainha e peciolo com muitos espinhos negros similares aos do estipe, porém maiores, com até $7 \mathrm{~cm}$ de comprimento. Inflorescência 3, intrafoliar, espigada; prófilo $13-17 \mathrm{~cm}$ de comprimento; bráctea peduncular $1,35,5-40 \mathrm{~cm}$ de comprimento, externamente esbranquiçada, coberta com escassos espinhos negros; pedúnculo $24,5-29 \mathrm{~cm}$ de comprimento. Flores em triades arranjadas por toda a raquila; flores estaminadas com 3 sépalas com lobos estreitados, 3 pétalas espatuladas, 6 estames; flores pistiladas com cálice cupular e corola tubular, a corola muito maior do que o cálice, com visivel anel estaminoidal. Frutos obovados, densamente arranjados na raquila, basalmente comprimidos e angulados, 20 ou mais unidades na raquila, epicarpo levemente rugoso, violáceo quando maduros, $1,1 \mathrm{~cm}$ de comprimento e $0,8 \mathrm{~cm}$ de diâmetro.

Dificilmente poder ser confundida com outras espécies de Bactris do Parque porque sempre apresenta inflorescência espigada e folhas com pinas regularmente arranjadas e dispostas em um mesmo plano. Embora os espinhos negros não achatados sejam similares aos de B. major, esta apresenta as pinas em mais de um plano e a inflorescência com 2-3 raquilas.

Exemplares representativos: E. Ferreira 486, E. Ferreira \& J. Bandeira 252, 496 .

\section{Bactris major Jacquin, Select. Stirp. Amer. Hist., ed. 2:134. 1780-1781.}

"Marajá"

Estipe cespitoso (11), 0,72-2,20m de comprimento e $2,1-2,2 \mathrm{~cm}$ de diâmetro, 
coberto desde a base por bainhas persistentes de folhas velhas muito fibrosas, comespinhos negros de até $4,2 \mathrm{~cm}$ de comprimento próximos aos nós. Folhas $5-6$, pinadas, $37-43$ pinas linear ou linearlanceoladas por lado, regularmente arranjadas e dispostas em mais de um plano, pinas medianas $30,5-38,5 \mathrm{~cm}$ de comprimento e $2-2,1 \mathrm{~cm}$ de largura; bainha $53 \mathrm{~cm}$ de comprimento, parcialmente fechada, muito fibrosa nas margens; peciolo $52 \mathrm{~cm}$ de comprimento; ráquis $1,25 \mathrm{~m}$ de comprimento; bainha, pecíolo e $1 / 3$ inicial da ráquis com muitos espinhos negros de secção arredondada, medindo até $10 \mathrm{~cm}$ de comprimento. Inflorescência 2, intrafoliar; prófilo 19,5-27cm de comprimento; bráctea peduncular $1,47,7-55 \mathrm{~cm}$ de comprimento, externamente esverdeada na ântese, cinza com frutos, coberta por escassos espinhos marrom-escuro e finos, com até $2 \mathrm{~cm}$ de comprimento; pedúnculo $35-42 \mathrm{~cm}$ de comprimento; ráquis ausente; raquilas $2-3,7,7-$ $10,4 \mathrm{~cm}$ de comprimento. Flores em triades irregularmente arranjadas entre flores estaminadas em pares ou solitárias ao longo das raquilas; flores estaminadas com 3 sépalas com lobos estreitos, 3 pétalas, 6 estames; flores pistiladas com cálice e corola tubulares, cálice geralmente mais comprido que a corola e densamente espinulosos; anel estaminoidal proeminente. Frutos elipsoidais, $26 \mathrm{ou}$ mais unidades por cacho, epicarpo levemente tomentoso, negro ou violáceo quando maduros.

Caracteriza-se pela inflorescência sem raque e com 2-3 raquilas, às vezes em forma de tridente. É uma espécie que requer áreas bem iluminadas para se desenvolver, sendo comum nos bordos da mata antropizada e capoeira alta, podendo também ocorrer em campo sujo, onde costuma formar touceiras densas com pouco mais de $1,5 \mathrm{~m}$ de altura.

Exemplares representativos: E. Ferreira \& J. Bandeira 253, 495.

\section{Bactris sp.}

Estipe cespitoso (8), 1,8-3,4m de comprimento e $1,9-2,5 \mathrm{~cm}$ de diâmetro, entre-nós com $2,5-4 \mathrm{~cm}$ de comprimento, com espinhos negro, não achatados, até $4 \mathrm{~cm}$ de comprimento, formando anéis próximos aos nós. Folhas 4-6, pinadas, 32-36 pinas linear-lanceoladas por lado; pinas basais e medianas irregularmente arranjadas em grupos de 2-7 e dispostas em vários planos; pinas apicais regularmente arranjadas e dispostas em um plano; pinas medianas $58-66,5 \mathrm{~cm}$ de comprimento e $3-3,5 \mathrm{~cm}$ de largura; bainha $20-24 \mathrm{~cm}$ de comprimento; pecíolo $70-80 \mathrm{~cm}$ de comprimento; ráquis $1,40 \mathrm{~m}$ de comprimento; espinhos escassos presentes apenas no pecíolo e base da ráquis. Inflorescência 1, intrafoliar; prófilo não visto; bráctea peduncular $1,45-53 \mathrm{~cm}$ de comprimento, coberta por espinhos negros não achatados dispostos espaçadamente; pedúnculo $31 \mathrm{~cm}$ de comprimento; ráquis $5 \mathrm{~cm}$ de comprimento; raquilas $15-25,12-16 \mathrm{~cm}$ de comprimento. Flores não vistas. Frutos (velhos) depressos-globosos.

A falta de flores e, principalmente, frutos maduros impediu a identificação 
desta espécie que estranhamente aparenta exibir características intermediárias entre $B$. brongniartii (disposição das raquilas na inflorescência e forma dos frutos) x B. major (espinhos negros não achatados e folhas com pinas dispostas em mais de um plano).

Exemplar representativo: E. Ferreira \& J. Bandeira 249.

\section{Socratea exorrhiza (Martius) H. Wendl., Bonplandia 8:103. 1860.}

"Paxiubinha"

Estipe solitário, $6-8 \mathrm{~m}$ de comprimento e $15-16 \mathrm{~cm}$ de diâmetro, cone de raizes adventícias na base com 1,45-2m de altura, as raizes densamente marromtomentosas quando novas, com numerosos acúleos curtos, cônicos, até $1 \mathrm{~cm}$ de comprimento. Folhas 7, pinadas, 17-18 pinas por lado, regularmente arranjadas, as pinas fendidas desde a base em diversos segmentos dispostos em vários planos, cada segmento com ápice premorso, segmentos usualmente com o ápice pêndulo; bainha fechada, formando um pseudo-caule esverdeado com $1,21-1,65 \mathrm{~m}$ de comprimento; pecíolo $35-42 \mathrm{~cm}$ de comprimento; ráquis 2,13-2,68m de comprimento. Inflorescência 1-2, infrafoliar; prófilo $46 \mathrm{~cm}$ de comprimento; bráctea peduncular 3, deiscentes, respectivamente com 18,5-29-42 cm de comprimento; pedúnculo $31-39 \mathrm{~cm}$ de comprimento; ráquis $6-12 \mathrm{~cm}$ de comprimento; raquilas 6-11, 15,5 (base)-41,2 (ápice)cm de comprimento. Flores em triades na base das raquilas; flores estaminadas com 3 sépalas triangulares, 3 pétalas ovadas e valvadas, 33 estames; flores pistiladas com 3 sépalas e 3 pétalas imbricadas. Frutos ovóides e cilíndricos, 2,4-3cm de comprimento e $1,6-1,9 \mathrm{~cm}$ de diâmetro, 39 ou mais unidades por cacho, às vezes até 15 unidades em uma raquila, epicarpo liso, verdeamarelado quando maduro, ocasião em que a casca se torna fendilhada.

Tipica por suas raízes adventicias muito longas, chegando a formar cones na base do estipe com até $2 \mathrm{~m}$ de altura. Característico também são as pinas divididas em segmentos com ápice premorso e a bainha das folhas fechadas formando um pseudo-caule esverdeado.

Exemplares representativos: E. Ferreira \& P. Silvio 292, 294, 295.

\section{Euterpe precatoria Martius in}

\section{A. D. Orb., Voy. Amérique Mér.} 7(3). Palmiers 10. 1842.

\section{"Açai"}

Estipe solitário, $9,5 \mathrm{~m}$ de comprimento e $15,3 \mathrm{~cm}$ de diâmetro, cone de raizes na base com ca. $40 \mathrm{~cm}$ de altura, as raízes densamente arranjadas, avermelhadas quando novas, sem acúleos. Folhas 17 , pinadas, 89-90 pinas lineares por lado, regularmente arranjadas, uniformente pêndulas desde a base; bainha fechada, formando um pseudo-caule esverdeado, $1,88 \mathrm{~m}$ de comprimento; peciolo $45 \mathrm{~cm}$ de comprimento; ráquis $3,47 \mathrm{~m}$ de comprimento. Inflorescência 3 , infrafoliar; prófilo n.v., deiscente; bráctea peduncular 1, deiscentes, n.v; pedúnculo $14 \mathrm{~cm}$ de comprimento; ráquis $56,3 \mathrm{~cm}$ de comprimento; raquilas 70, 68,5 (base)- 30 (ápice) $\mathrm{cm}$ de comprimento. Flores em tríades na base das raquilas, somente estaminadas na porção distal; flores estaminadas com 3 sépalas ovadas, livres 
e imbricadas, 3 pétalas ovadas, livres e valvadas, 6 estames; flores pistiladas com 3 sépalas e 3 pétalas ovadas, imbricadas, similares em tamanho. Frutos globosos, ca. $1 \mathrm{~cm}$ de diâmetro, cor roxo-púrpura quando maduros, residuo estigmático sub-apical.

Uma das espécies de palmeiras mais comuns no Acre, podendo ser identificada pelas suas folhas com pinas estreitas e pendentes e o estipe delgado, esbranquiçado, normalmente alcançando o dossel da mata quando as plantas são adultas.

Exemplar representativo: E. Ferreira \& P. Sílvio 296.

\section{Geonoma acaulis Martius, Hist. Nat. Palm. 2:18. 1823.}

Acaule. Folhas 6-9, pinadas, 3-6 pinas semi-sigmóideas por lado, regularmente arranjadas e dispostas em 1 plano; bainha aberta, $3-7,5 \mathrm{~cm}$ de comprimento; pecíolo $44,5-93 \mathrm{~cm}$ de comprimento; ráquis $29-39 \mathrm{~cm}$ de comprimento. Inflorescência 1, espigada, intrafoliar; prófilo $7,4-11 \mathrm{~cm}$ de comprimento, envolvendo o pedúnculo e parte da bráctea peduncular; bráctea peduncular 1 , $12,5-22 \mathrm{~cm}$ de comprimento; pedúnculo $45,4-94 \mathrm{~cm}$ de comprimento; ráquis $6,5-$ $22 \mathrm{~cm}$ de comprimento, ereta na ântese. Flores em tríades dentro de alvéolos florais densamente arranjados em forma espiral ao longo da ráquis; flores estaminadas com 3 sépalas ovadas, livres e imbricadas, 3 pétalas ovadas, parcialmente soldadas na base, livres e valvadas no ápice, 6 estames; flores pistiladas com 3 sépalas lanceoladas, livres e imbricadas, 3 pétalas soldadas por cerca de $2 / 3$ do seu comprimento, livres e valvadas acima; anel estaminoidal apicalmente digitado-lobado. Frutos globosos, menos de $1 \mathrm{~cm}$ de diâmetro, epicarpo irregular e negro, quando maduro.

Muito comum na mata de terra firme e inundável, sendo a única espécie acaule e sem espinhos que cresce no Parque. Skov (1989) e mais recentemente Henderson (1995), consideram esta espécie uma variedade de $G$. macrostachys, da qual se diferencia basicamente por apresentar folhas pinadas com pinas sigmóideas. Decidiu-se usar aqui a designação $G$. acaulis porque o grupo de espécies a qual a mesma pertence é extremamente variável na forma das folhas e do ápice estéril dainflorescência, comprimento e diâmetro da ráquis e arranjo dos alvéolos florais. Somente uma revisâo mais detalhada de todo o grupo poderá oferecer uma solução aceitável para este problema.

Exemplares representativos: E. Ferreira 247, E. Ferreira \& J. Bandeira 251, 257, E.

Ferreira \& P. Sílvio 290, 291.

\section{Geonoma deversa (Poit.) Kunth, Enum. P1. 3:321. 1841.}

"Ubim" [Fig. 3c]

Estipe cespitoso (13), 1,6-2,7m de comprimento e $1-1,2 \mathrm{~cm}$ de diâmetro. Folhas 9 , pinadas, 3 pinas falcadas por lado, dispostas em 1 plano; bainha aberta, $9-12,5 \mathrm{~cm}$ de comprimento, fibrosa nas margens; peciolo $17-19 \mathrm{~cm}$ de comprimento; ráquis $32,5-38 \mathrm{~cm}$ de comprimento. Inflorescência 2, intrafoliar, ramificada; prófilo n.v.; bráctea peduncular 1 , n.v, deiscente; pedúnculo $6,5-6,6 \mathrm{~cm}$ de comprimento; ráquis $8-8,3 \mathrm{~cm}$ de comprimento; raquilas $13-14,18,8-23,1 \mathrm{~cm}$ 


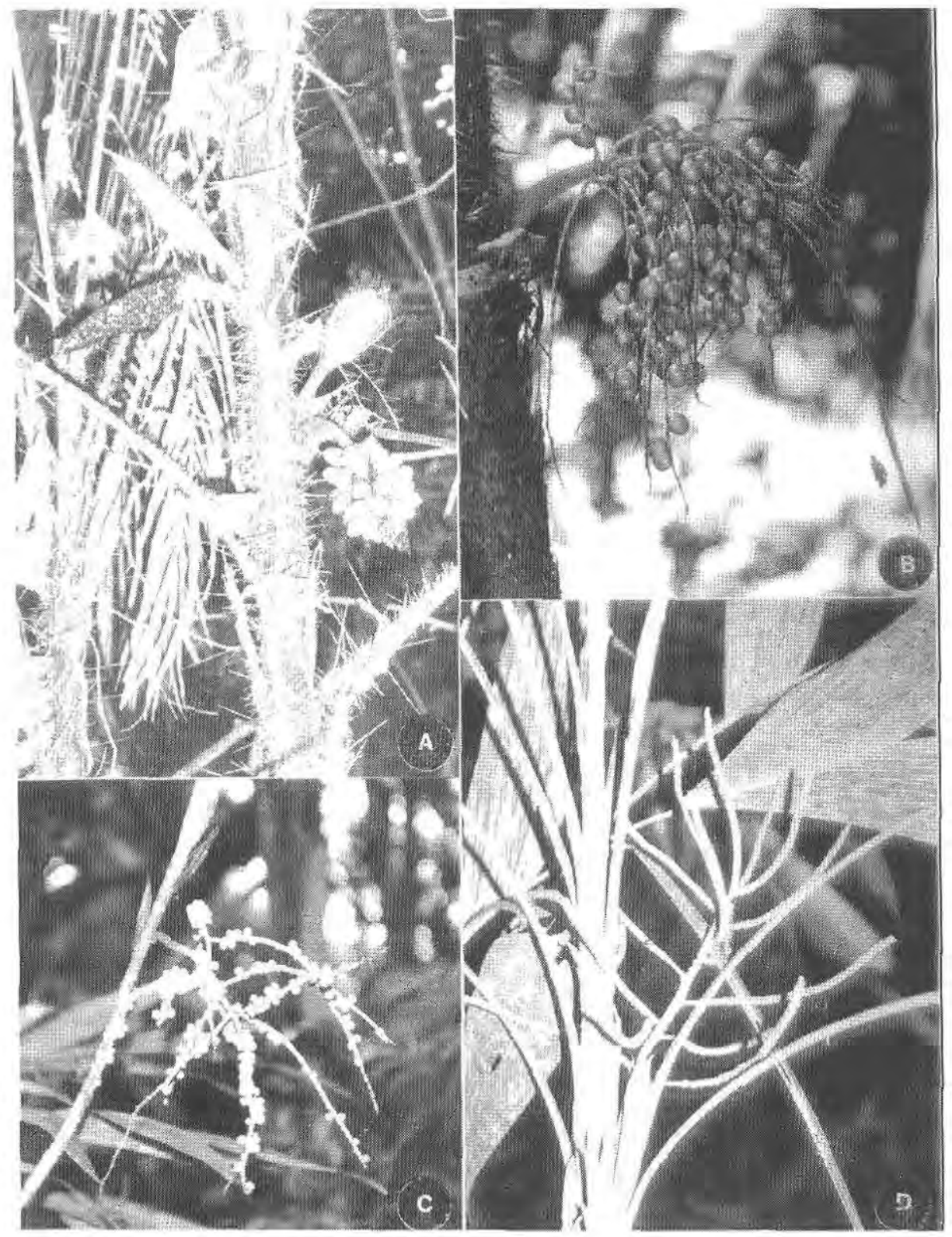

Figura 3. Palmeiras do Parque Nacional do Seringuciro, A. Bactris concinna; B. Bactris brongniartii; C. Geonoma deversa; D. Geonoma juruana. 
de comprimento. Flores em triades dentro de alvéolos florais verticilados, os verticilos dispostos em intervalos regulares ao longo das raquilas; flores estaminadas com 3 sépalas e 3 pétalas ovadas, 6 estames; flores pistiladas com 3 sépalas e 3 pétalas ovadas, o estigma exerto; anel estaminoidal apicalmente crenado. Frutos globosos, $0,4 \mathrm{~cm}$ de diâmetro (verdes), epicarpo irregular, roxoenegrecido quando maduro.

A mais comum das espécies de Geonoma no Acre. Facilmente identificada pelas suas folhas com as pinas falcadas e as raquilas com alvéolos florais verticilados.

Exemplar representativo: E. Ferreira \& J. Bandeira 256.

\section{Geonoma juruana Dammer, Verh. Bot. Ver. Brandenb. 48:119. 1906.}

Estipe cespitoso (3-5), 1,3-22m de comprimento e 1,2-1,3cm de diâmetro. Folhas 10-13, pinadas, 2-4 pinas levemente sigmóides, dispostas em 1 plano, as pinas apicais e basais mais largas, $49,5 \mathrm{~cm}$ de comprimento $\times 7,3 \mathrm{~cm}$ de largura, intercaladas por 1-2 pinas mais estreitas, $32,5-35 \mathrm{~cm}$ de comprimento x 1-1,5cm de largura; bainha 6$8,5 \mathrm{~cm}$ de comprimento, fibrosa nas margens; peciolo $25,5-31 \mathrm{~cm}$ de comprimento; ráquis $25,5-29 \mathrm{~cm}$ de comprimento. Inflorescência intrafoliar na ântese, infrafoliar com frutos, ramificada; prófilo $10-10,5 \mathrm{~cm}$ de comprimento; bráctea peduncular $1,7,5$ $9,5 \mathrm{~cm}$ de comprimento; pedúnculo 7,5$9 \mathrm{~cm}$ de comprimento; ráquis $10-12 \mathrm{~cm}$ de comprimento; raquilas $8-24,6,4$ $14,6 \mathrm{~cm}$ de comprimento, cor laranja com frutos. Flores em triades dentro de alvéolos florais arranjados em espiral ao longo das raquilas, as flores estaminadas e pistiladas com similar forma e tamanho; flores estaminadas com 3 sépalas e 3 pétalas ovadas ou linearlanceoladas, 6 estames exertos; flores pistiladas com 3 sépalas lanceoladas e 3 pétalas ovadas, o estigma exerto; anel estaminoidal apicalmente digitadolobado. Frutos elipsoidais quando verdes e sub-globosos quando maduros, cor verde-amarelados, $0,7-0,9 \mathrm{~cm}$ de comprimento e $0,4-0,6 \mathrm{~cm}$ de diâmetro.

G. juruana se caracteriza por suas folhas com pinas basais e apicais muito largas e 1-2 pinas intermediárias bem mais estreitas. Os frutos geralmente adquirem uma cor verde-amarelada quando maduros. Esta espécie faz parte de um grupo extremamente complexo dentro de Geonoma, que inclui, entre outras, G. maxima, G. chelidonura e G.spixiana. Todas elas podem apresentar variação de forma nas folhas (inteiras, com poucas pinas largas ou regularmente pinadas) e morfologia da inflorescência (ordem de ramificação, forma e disposição dos alvéolos florais).

Exemplares representativos: E. Ferreira 244, E. Ferreira \& J. Bandeira 250,493 .

\section{Geonoma maxima (Poit.) Kunth, Enum. Pl. 3:229. 1841.}

\section{"Palmeirinha"}

Estipe cespitoso (25), 2,2-4,2m de comprimento e $1-1,5 \mathrm{~cm}$ de diâmetro. Folhas 9-10, pinadas, $12-14$ pinas lineares e levemente sigmóides, dispostas em 1 plano, pinas medianas $45 \mathrm{~cm}$ de comprimento $\mathrm{x} 1-1,3 \mathrm{~cm}$ de largura; bainha 6-8,5cm de comprimento; pecíolo $23-$ 
$41 \mathrm{~cm}$ de comprimento; ráquis $42,5-50 \mathrm{~cm}$ de comprimento. Inflorescência intrafoliar na ântese e com frutos, ramificada; prófilo $9,3 \mathrm{~cm}$ de comprimento; bráctea peduncular $1,8,8 \mathrm{~cm}$ de comprimento, inserida $0,5 \mathrm{~cm}$ acima do prófilo; pedúnculo 8 $9 \mathrm{~cm}$ de comprimento; ráquis $5,5-9 \mathrm{~cm}$ de comprimento; raquilas $4,12-14.5 \mathrm{~cm}$ de comprimento, cor avermelhada na ântese. Flores em tríades dentro de alvéolos florais arranjados em espiral ao longo das raquilas, as flores estaminadas e pistiladas com similar forma e tamanho; flores estaminadas com 3 sépalas e 3 pétalas lanceoladas, 6 estames exertos; flores pistiladas com 3 sépalas e 3 pétalas ovadas ou lanceoladas, o estigma exerto; anel estaminoidal apicalmente digitadolobado. Frutos ovóides ou globosos quando maduros, negro-púrpura quando maduros, $0,9 \mathrm{~cm}$ de comprimento e 0,6 $0,7 \mathrm{~cm}$ de diâmetro.

Apresenta folhas regulamente pinadas e frutos de cor quase negra quando maduros, caracteres que ajudam a distingui-la de G. juruana.

Exemplares representativos: E. Ferreira 243, E. Ferreira \& J. Bandeira 492.

\section{Oenocarpus bataua Martius,} Hist. Nat. Palm. 2:23. 1823.

\section{"Patoá"}

Estipe solitário, colunar, $7 \mathrm{~m}$ de comprimento e $17 \mathrm{~cm}$ de diâmetro. Folhas 14, pinadas, 143 pinas linearlanceoladas por lado, dispostas em 1 plano, pinas medianas $1,22 \mathrm{~m}$ de comprimento $\times 9,8 \mathrm{~cm}$ de largura; bainha $0,85 \mathrm{~m}$ de comprimento, fibrosa, fibras finas, negras e densas, entremeadas por fibras grossas muito rígidas (talas); pecíolo $72 \mathrm{~cm}$ de comprimento; ráquis $5,96 \mathrm{~m}$ de comprimento. Inflorescência infrafoliar, hipuriforme; prófilo n.v.; bráctea peduncular 1 , decídua, n.v.; pedúnculo $17 \mathrm{~cm}$ de comprimento; ráquis $33 \mathrm{~cm}$ de comprimento; raquilas numerosas, as basais com até $92,5 \mathrm{~cm}$ de comprimento e 18 frutos, as medianas $96,5 \mathrm{~cm}$ de comprimento e 27 frutos, as apicais $87 \mathrm{~cm}$ de comprimento e 22 frutos. Flores em triades na base das raquilas, flores estaminadas em pares ou solitárias no ápice; flores estaminadas com 3 sépalas triangulares, 3 pétalas ovadas, 12-15 estames; flores pistiladas com 3 sépalas e 3 pétalas largamente ovadas, tamanho similar ou sépalas levemente maiores. Frutos oblongos ou levemente elipsóides, negro-púrpura quando maduros, $2,3 \mathrm{~cm}$ de comprimento $\mathrm{e}$ $1,3 \mathrm{~cm}$ de diâmetro.

Típica das áreas mais úmidas, $O$. bataua é geralmente uma espécie de porte massivo. Caracteriza-se pela sua inflorescência de forma hipuriforme e as folhas com pinas muito largas regularmente arranjadas e dispostas em um mesmo plano.

Exemplar representativo: E. Ferreira \& P. Silvio 287.

\section{Oenocarpus minor Martius,}

\section{Hist. Nat. Palm. 2:25. 1823.}

"Bacabinha"

Estipe cespitoso (2), 4-6m de comprimento e 7,2cm de diâmetro. Folhas 8 , pinadas, 47-55 pinas lineares por lado, dispostas em mais de 1 plano, pinas medianas $61 \mathrm{~cm}$ de comprimento $\times 5 \mathrm{~cm}$ de largura; bainha $55 \mathrm{~cm}$ de comprimento, fibrosa nas margens, fibras curtas e grossas 
porém não rígidas; pecíolo $46 \mathrm{~cm}$ de comprimento; ráquis $2,5 \mathrm{~m}$ de comprimento; bainha, pecíolo e ráquis com tomentos marrom-avermelhados. Inflorescência infrafoliar, hipuriforme; prófilo n.v.; bráctea peduncular 1 , decídua, n.v.; pedúnculo $5,4 \mathrm{~cm}$ de comprimento; ráquis $7,4 \mathrm{~cm}$ de comprimento; raquilas 54 , as medianas $58 \mathrm{~cm}$ de comprimento e 13 frutos, densamente cobertas por tomento granulado-avermelhado. Flores em triades na base das raquilas, flores estaminadas em pares ou solitárias no ápice; flores estaminadas com 3 sépalas triangulares, 3 pétalas ovadas, 6 estames; flores pistiladas com 3 sépalas e 3 pétalas largamente ovadas, de tamanho similar. Frutos globosos, negro-púrpura quando maduros, $1,8 \mathrm{~cm}$ de diâmetro.

As plantas encontradas no Parque constituem o primeiro registro da espécie para o Acre, o que extende a sua distribuição ainda mais para o oeste da região Amazônica. É extremamente similar a $O$. mapora, da qual pode ser diferenciada apenas pelo porte, em geral bem menor. É sabido que hibridos podem ocorrer em Oenocarpus (Balick, 1991), portanto, embora os espécimens coletados no Parque apresentassem diferenças consistentes, é possível que individuos intermediários ocorram, tornando muito difícil a segregação das duas espécies. Henderson (1995), sugere que estas duas espécies são co-específicas e $O$. minor, por ter sido publicada anteriormente, deve ser a correta denominação de espécimens pertencentes a este grupo.

Exemplar representativo: E. Ferreira \& J. Bandeira 513.

\section{Oenocarpus mapora Karsten, Linnaea 28:274. 1857.}

"Bacaba"

Estipe cespitoso (2-4), 6-8m de comprimento e $8-8,5 \mathrm{~cm}$ de diâmetro. Folhas 5-8, pinadas, 66-68 pinas lineares por lado, as apicais regularmente arranjadas e dispostas em 1 plano, as medianas e basais irregularmente arranjadas em grupos de 2-3 e dispostas em mais de 1 plano; bainha $63-73 \mathrm{~cm}$ de comprimento, verde-arroxeado ou marrom-escuro, fibrosa nas margens, fibras marrons, curtas e grossas porém não rígidas; peciolo $40-63 \mathrm{~cm}$ de comprimento; ráquis $2,96-3,43 \mathrm{~m}$ de comprimento; bainha, peciolo e ráquis marromtomentosos. Inflorescência infrafoliar, hipuriforme; prófilo $43 \mathrm{~cm}$ de comprimento; bráctea peduncular 1 , decidua, $83 \mathrm{~cm}$ de comprimento, incluindo o ápice agudo de $10 \mathrm{~cm}$, escassamente marrom-tomentosa; pedúnculo $6,5-10 \mathrm{~cm}$ de comprimento; ráquis $6-8 \mathrm{~cm}$ de comprimento; raquilas $68-73,51-62 \mathrm{~cm}$ de comprimento; pedúnculo, raque e raquilas marrom-tomentosos. Flores em triades na base dasraquilas com flores estaminadas em pares ou solitárias no ápice; flores estaminadas com 3 sépalas triangulares, 3 pétalas ovadas, 6 estames; flores pistiladas com 3 sépalas e 3 pétalas largamente triangulares, sépalas maiores que as pétalas. Frutos globosos-elipsoidais, negro-púrpura quando maduros, $1,5 \mathrm{~cm}$ de diâmetro.

Apresenta inflorescência de forma hipuriforme densamente marromtomentosa que contrasta fortemente com os frutos que se tornam quase negros quando maduros. O. mapora é uma espécie mais amplamente distribuida no Acre que $O$. minor e na região de Cruzeiro 
do Sul (vale do rio Juruá) às vezes pode ser confundida com $O$. balickii.

Exemplar representativo: E. Ferreira \& J. Bandeira 514.

\section{Maximiliana maripa (Aubl.)}

Drude in Martius, FI. Bras.: Cyclanthaceae et Palmae I,

fasc. 85 , vol 3(2):452.

"Najá" [Fig. 2b]

Estipe solitário, 1,13-10m de comprimento e 15,3-22,7cm de diâmetro, liso, colunar. Folhas 10-14, pinadas, 231 pinas lineares por lado, irregularmente arranjadas em grupos de 3-5 e dispostas em vários planos; bainha $0,80-0,90 \mathrm{~m}$ de comprimento; peciolo $1,71-2,00 \mathrm{~m}$ de comprimento; raque $4,50-4,76 \mathrm{~m}$ de comprimento; pecíolo e raque com bordos cortantes. Inflorescência 2-3, intrafoliar na ântese, geralmente as inflorescências velhas persistem em bainhas de folhas velhas; inflorescências estaminadas desenvolvendo-se em bainha de folhas acima do ponto de desenvolvimento das inflorescências predominantemente pistiladas; inflorescênciapistilada com prófilo até $1,6 \mathrm{~m}$ de comprimento; bráctea peduncular 1 , com até $2,5 \mathrm{~m}$ de comprimento, incluindo o ápice ponteagudo, sulcada externamente; pedúnculo $0,96 \mathrm{~m}$ de comprimento; raque $0,36-0,68 \mathrm{~m}$ de comprimento; raquilas mais de 254, densamente cobertas por tomentos em forma de lã de cor amarelo-ouro, dispostas em todos os lados da raque, raquilas basais com $16 \mathrm{~cm}$ de comprimento, raquilas apicais com $19 \mathrm{~cm}$ de comprimento. Flores estaminadas com 3 sépalas triangulares imbricadas, 3 pétalas lanceoladas de $4 \mathrm{~mm}$ de comprimento e 6 estames exertos de até $8 \mathrm{~mm}$ de comprimento; flores pistiladas com até $1,5 \mathrm{~cm}$ de comprimento, 3 sépalas e 3 pétalas largamente ovadas, as sépalas ligeiramente maiores que as pétalas. Frutos oblongo-elipsóides, até $7 \mathrm{~cm}$ de comprimento, cor marrom-amarelada quando maduros, geralmente com perianto recobrindo cerca da metade do comprimento do fruto.

Espécie muito comum em toda a região de Plácido de Castro, especialmente em áreas de pastagens onde pode formar grandes grupos. Parece preferir áreas mais secas pois dentro do Parque foi clara a sua ausência na mata primária inundável.

Wessels Boer (1988) e Henderson (1995) consideram Attalea como o único gênero válido em Attaleinae, sub-tribo que inclui Attalea, Scheelea, Orbignya e Maximiliana. Entretanto Maximiliana é o único gênero do grupo a apresentar consistentemente estames exertos e frutos com fibras do endocarpo pouco evidentes. Outras caracteristicas tais como a forma da bráctea peduncular e bordos cortantes do peciolo e porção basal da ráquis foliar tornam-a claramente distinta de todas as outras. Como proposto em Henderson (1985), uma revisão de toda Attaleinae éindispensável para se entender melhor o grupo. Mudanças só se justificarão plenamente após tal revisão.

Exemplares representativos: E. Ferreira \& P. Silvio 293, 298.

\section{Attalea butyracea (Mutis ex L.f.) Wess. Boer, Pittiera 17:312.}

\section{"Jaci"}

Estipe solitário, 5-10m de comprimento e $15-23 \mathrm{~cm}$ de diâmetro, colunar, com bainhas persistentes de folhas caidas no $1 / 3$ final. Folhas 15 , 
pinadas, dispostas sempre de forma ascendentes, 201 pinas lineares por lado, regularmente arranjadas e dispostas em 1 plano; bainha ca, $1,5 \mathrm{~m}$ de comprimento, fibras grossas nas margens; peciolo ausente; ráquis 9,09 m de comprimento, usualmente com o ápice arqueado. Inflorescência intrafoliar, inflorescências estaminadas desenvolvendo-se em bainha de folhas acima do ponto de desenvolvimento das inflorescências predominantemente pistiladas, estas muito mais robustas; inflorescência pistilada prófilo n.v.; bráctea peduncular 1 , ca. $2 \mathrm{~m}$ de comprimento, sulcada externamente; pedúnculo ca. $1,5 \mathrm{~m}$ de comprimento; raque $1,2 \mathrm{~m}$ de comprimento, $7 \mathrm{~cm}$ de diâmetro na base; raquilas mais de 150 , dispostas em todos os lados da raque. Flores estaminadas com 3 sépalas triangulares imbricadas, $1-2 \mathrm{~mm}$ de coprimento, 3 pétalas lineares, secção quase circular, $1,5 \mathrm{~cm}$ de comprimento e 6 estames; flores pistiladas com até $2,5 \mathrm{~cm}$ de comprimento, 3 sépalas e 3 pétalas triangulares, as sépalas ligeiramente maiores que as pétalas. Frutos oblongo ou ovóides, até $11 \mathrm{~cm}$ de comprimento, cor marrom-amarelada ou rosado quando maduros.

Palmeira de porte massivo caracterizada por suas folhas ascendentes com ápice arqueado e pinas regularmente arranjadas e dispostas em um mesmo plano. Embora tenha sido encontrada em mata antropizada, é mais comum em áreas de pastagens ou locais bem iluminados.

Exemplar representativo: E. Ferreira \& J. Bandeira 515.

\section{DISCUSSÃO}

Quando comparada com a recentemente publicada flora de palmeiras da Reserva Florestal Ducke (Henderson \& Scariot, 1993), observase que o Parque Natural do Seringueiro apresenta uma alta diversidade genérica e específica de palmeiras (Tab, 3) e que a região de Plácido de Castro é potencialmente uma importante área de diversificação desta familia de plantas. Infelizmente o Parque Natural do Seringueiro é a única área de preservação ambiental legalmente protegida de qualque classe de exploração ou destruição em todo o Município de Plácido de Castro. O Projeto de Assentamento Extrativista Porto Dias, localizado a $50 \mathrm{~km}$ a NE do Parque e com pouco mais de 22.000 hectares, por definição legal permite a exploração e uso de seus recursos naturais. O estabelecimento de novas áreas de proteção, sejam novos Parques ou mesmo Reservas Ecológicas de uso público restrito dentro do Município de Plácido de Castro é uma medida necessária e urgente, demonstrada aqui pela alta diversidade de palmeiras ali encontradas e pelo alto índice de destruição das florestas nativas que se verifica em toda a região do referido Município.

Tabela 3. Flora de palmeiras: Parque do Seringueiro x Reserva Duck.

\begin{tabular}{lcccl}
\hline & Área (ha) & Gêneros & Espécies & Localização \\
\hline Parque do Seringueiro & 45 & 10 & 22 & Amazônia Ocidental \\
Reserva Ducke & 10.000 & 14 & 35 & Amazônia Central
\end{tabular}




\section{AGRADECIMENTOS}

Trabalho de campo apoiado pela Divisão de Unidades de Conservação do Instituto de Meio Ambiente do Acre, Prefeitura Municipal de Plácido de Castro e Convênio UFACT The New York Botanical Garden. Jurandir Teles Machado, José de Ribamar Bandeira e Pedro Sílvio ajudaram no planejamento, elaboração do mapa de localizaçâo e coletas das amostras botânicas. Andrew Henderson e Francis Kahn ajudaram na identificação das amostras in situ. Douglas Daly deu valiosas sugestōes ao manuscrito original.

\section{Bibliografia citada}

Balick, M. 1991. A new hybrid palm from Amazonian Brazil, Oenocarpus $x$ andersonii. Bol Mus. Paraense Hist. Nat. 7:505-510.

Brasil. 1976. Ministério das Minas e Energia. Departamerto Nacional de Produção Mineral. Projeto RADAMBRASIL. Folha SC. 19 Rio Branco; geologia, geomorfologia, pedologia, vegetação, uso potencial da terra, Rio de Janeiro, 458p. (Levantamento de Recursos Naturais., 12).
Burret, M. 1933-1934. Bactris und verwandte palmengattungen. Repert. Spec. Nov. Regni Veg., 34:167-184, 185-253.

Burret, M. 1934. Die palmengattung Astrocaryum G. F. W. Meyer. Repert. Spec, Nov. Regni Veg., 35:114-158.

Funtac. Fundação de Tecnologia do Estado do Acre. 1990. Monitoramento da cobertura florestal do Estado do Acre: desmatamento e uso atual da terra. Rio Branco. $214 \mathrm{p}$.

Henderson, A.; Scariot, A, 1993. A flórula da Reserva Ducke, I: Palmae (Arecaceae). Acta Amazonica 23(4):349-369.

Henderson, A. 1995. The palms of the Amazon. New York, Oxford. 362p.

Oliveira, V. H. de.; Alvarenga, M. I. N. 1985. Principais solos do Acre. Rio Branco, EMBRAPA-UEPAE de Rio Branco, 40p.

Skov, F. 1989. Hypertaxonomy-a new tool for revisional work and a revision of Geonoma (Palmae) in Ecuador. Dissertação de $\mathrm{PhD}$., Aarhus University, Dinamarca. 19Ip.

Wallece, A. 1853. Palm trees of the Amazon and their uses. London, Van Hoorst. 129p.

Wessels Boer, J. 1988. Palmas indigenas de Venezuela. Pittiera, 17:1-332, 